\title{
Percepção e Ontogênese: modulações transdisciplinares da subjetividade
}

Universidade Federal Fluminense, Rio das Ostras, RJ, Brasil

\section{Resumo}

Atravessando as principais teorias e sistemas da psicologia onde o problema da percepção é abordado, não se verifica uma dedicação profunda aos processos por meio dos quais os fenomenos perceptivos são constituídos. Predomina ai o pressuposto da percepção e do objeto percebido como elementos "dados" ontologicamente, ou seja, já constituídos previamente à experiência perceptiva. Na contramão desta abordagem ontológica, buscaremos compreender os processos ontogenéticos através dos quais os fenômenos perceptivos são criados, estruturam-se e modificam-se. Para isso, abordaremos a percepção a partir de uma perspectiva transdisciplinar onde ressoam elementos da biologia, etologia, filosofia e artes. No centro dessa investigação, o corpo emerge como sede dos processos cognitivos e foco das intervenções clínicas, como meio de constituição e transformação da subjetividade.

Palavras-chave: percepção; ontogênese; transdisciplinaridade; corpo; subjetividade.

\section{Perception and Ontogenesis: transdisciplinary modulations of subjectivity}

\begin{abstract}
Crossing the main theories and systems of psychology where the problem of perception is discussed, there is not a deep commitment to the processes by which the perceptual phenomena are constituted. There prevails the assumption of perception and perceived object as ontologically "given" elements, i.e., constituted previously to the perceptual experience. Against this ontological approach, we seek to understand the ontogenetic processes through which the perceptual phenomena are created, structured and modified. In order to do so, we will address the perception from a transdisciplinary perspective which resounds elements of biology, ethology, philosophy and arts. In the center of this investigation, the body emerges as source of cognitive processes and focus of clinical interventions as a means of formation and transformation of subjectivity.
\end{abstract}

Keywords: perception; ontogenesis; transdisciplinarity; body; subjectivity.

No conjunto da produção de conhecimento dos sistemas e teorias da psicologia, o fenômeno da percepção não encontrou, até os dias atuais, uma forma ampla de compreender sua gênese e os processos contínuos que contribuem para sua transformação (PENNA, 1973; FERREIRA, 2010; KASTRUP, 1999; SIMONDON, 2005). Assim, do associacionismo ao behaviorismo, do gestaltismo às ciências e tecnologias da cognição, a psicologia compôs, em sua diversidade, uma convergência que restringe os processos perceptivos a uma abordagem utilitarista da subjetividade (PENNA, 1973; FERREIRA, 2010). Estática ou dinâmica, a percepção resulta frequentemente num processo que supõe como já constituído ontologicamente tanto as funções cognitivas de apreensão dos dados que compõem o mundo, assim como o próprio mundo que se oferece dado ou pronto para ser percebido. Ou seja, o que é percebido neste processo apresenta-se como um recorte "útil" do "mundo" para uma ação apropriada daquele que percebe.

Nesta perspectiva, mesmo na Psicologia da Gestalt (GUILLAUME，1960; WERTHEIMER, 1980; KOFFKA, 1975), onde a percepção constitui o alvo principal das suas investigações, as "figuras" que emergem do "fundo" são imediatamente reconhecidas como algo que já possui existência e designação linguística, ou seja, emergem prontamente como representações para aquele

\footnotetext{
^Endereço para correspondência: Universidade Federal Fluminense, Polo Universitário de Rio das Ostras. Rua Recife, s/n - Jardim Bela Vista. Rio das Ostras, RJ - Brasil - Caixa-postal: 28890000. CEP: 28895-532. E-mail: danilomelo.uff@gmail.com
}

que percebe. Tais representações são consideradas como "totalidades" que resultam da (re)organização do campo perceptivo a partir da lei "fundamental" da Boa Forma. De acordo com tal fundamento, as forças de organização da percepção tendem a um equilíbrio estático que resulta sempre na "melhor forma", não restando aí qualquer lugar para a criação de uma "figura improvável" (DELEUZE, 2007). Para Simondon $(2005,2006,2012)$, tal modelo de "equilíbrio estável", no qual os potenciais de gênese e transformação da percepção tendem a se esgotar na reorganização do campo problemático que dá pregnância às formas, surge como resolução de um problema num campo tensional. Neste sentido, Simondon argumenta que a psicologia da Gestalt desconhece um outro modelo que lhe possibilitaria pensar a continuidade dos processos de criação da percepção, o "equilíbrio metaestável". Por outro lado, do ponto de vista prático, nos experimentos conduzidos por Köhler (1978) com chimpanzés, as situações problemáticas já continham em si as possibilidades de resolução, considerando inteligente o animal que "compreendesse" o problema e o solucionasse, isto é, que ao reorganizar a "percepção" tivesse subitamente a chave geral de "ação" para resolver o problema (imediata ou progressivamente) e assim reduzir a tensão a um nível mínimo, restaurando a estabilidade do equilíbrio.

Este modo recorrente de tratar a percepção mostra como a psicologia manteve-se aprisionada ao modelo clássico de ciência, encerrando o conhecimento num paradigma dicotômico que separa e opõe sujeito e objeto. 
É, portanto, a partir do pressuposto da existência de um sujeito que percebe e de um objeto que pode ser percebido que a psicologia apoiou, em suas diversas abordagens, o problema da percepção. Neste sentido, perceber torna-se sinônimo de conhecer e o conhecimento, na ordem dos organismos vivos, visa à adaptação e "adaptar-se é tornar-se gradativamente mais adequado a um mundo que preexiste" (DO EIRADO et al., 2006, p. 80).

A percepção, então, estabiliza a imagem do mundo para favorecer uma ação, efetiva ou simplesmente elaborada, que possa tirar proveito da situação em que o organismo está inserido, havendo, de um lado, o "agente" que percebe, e de outro, o "estímulo" percebido, como, por exemplo, nos funcionalismos, behaviorismos e no interacionismo piagetiano. Enquanto ciências da adaptação, estas abordagens tomam seu modelo científico da Biologia, preocupando-se com o ajustamento dos organismos a seu meio ambiente (PENNA, 1973; FERREIRA, 2010; SIMONDON, 2005). Para elas, a percepção é duplamente funcional, pois é uma função do organismo e tem uma finalidade que é adaptativa e se conclui na ação, seja no modelo do reflexo de Dewey (1971), no operante de Skinner (1974) ou nos esquemas sensório-motores de Piaget (1961). Em todas elas a percepção é parte integrante da atividade, embora com recortes funcionais diferentes.

Encontramos ainda no Cognitivismo (PENNA, 1999; FERREIRA, 2010; SEIDL DE MOURA; CORRÊA, 1997) uma perspectiva que reduz o fenômeno perceptivo a um "padrão de estímulos" ao qual deve corresponder um "padrão de respostas", pressupostas ou constituídas, em função da resolução de um problema, isto é, da adaptação. O que importa aí é o processamento mental que, por um lado, analisa as formas de organização das diferentes propriedades das entradas sensoriais (input) e, por outro, seleciona ou produz as respostas/ações (output) correlativas à solução do problema em questão. Com isso, "o estudo da psicologia (cognitiva) buscou identificar a que propriedade estrutural do ambiente está relacionado o comportamento: nós reduzimos o mundo para agir nele" (DO EIRADO et al., 2010, p. 86).

$\mathrm{Na}$ escala humana, a despeito da complexidade dos processos cognitivos, a coerência entre a percepção e o mundo percebido não só viabiliza as adaptações do indivíduo como também se torna condição do estabelecimento de padrões de normatização, os quais, por sua vez, determinam as formas adaptativas da subjetividade nas diversas sociedades e culturas (CANGUILHEM, 2003; FOUCAULT, 1999). É justamente em consonância com esta perspectiva adaptacionista que se funda o projeto da psicologia como ciência, compreendendo a percepção do mundo e o próprio mundo como uma totalidade ou uma junção de pequenas totalidades. Depreende-se daí que os divergentes projetos da psicologia, que consideram de diferentes formas o problema da percepção, abordam-na a partir de um horizonte comum caracterizado pela homogeneidade e pela estabilidade (FERREIRA, 2010).

Consideramos este modo de abordar a percepção como uma certa posição política a partir da qual a subjetividade (enquanto funcionamento conjunto dos diversos processos cognitivos) deve ser compreendida (KASTRUP; TEDESCO; PASSOS, 2008). Esta política, que visa tão somente os aspectos utilitários e adaptativos da percepção, se concilia com os dispositivos coletivos de normatização que servem para regular os modos de relação dos indivíduos com o meio em que estão inseridos de acordo com as diferentes formações socioculturais das quais fazem parte. Nesta perspectiva, a percepção torna-se subsumida pela "forma da representação" e serve ao "modelo da recognição", instaurando um "senso comum" que é compartilhado sob a forma de um "bom senso", constituindo assim o conjunto das representações sociais. O que a representação e a recognição operam sobre a subjetividade, de acordo com Deleuze (1988), é uma certa "conformidade" em relação aos aspectos "dados" do senso comum, levando os indivíduos a tomar como natural o conjunto das representações melhor compartilhadas no meio social em que vivem. Apoiada sobre esta perspectiva, a psicologia "formou uma concepção representacional da subjetividade: pensamos, sentimos, agimos para nos adequar a ou transformar um mundo que supostamente subsiste independentemente do sujeito que o experimenta" (DO EIRADO et al., 2010, p. 86).

De algum modo, este processo coincide com a "evidência" de que o indivíduo já experimenta, concretamente, uma dupla "naturalização": 1) do fato de que ele percebe, e 2) do fato de que o que ele percebe está em conformidade com o que é percebido pelos outros indivíduos que compartilham o mesmo meio, o que viabiliza e é viabilizado pelas formas de comunicação. É, portanto, com base nesta "dupla natureza", possivelmente evidenciada na experiência dos indivíduos, que a psicologia apoia suas construções teóricas e experimentais, favorecendo com isso uma "política normativa da percepção", isto é, uma posição na qual a compreensão da subjetividade está subsumida a dispositivos coletivos de regulação adaptativa que estabelecem relações utilitárias dos indivíduos com o meio em que estão inseridos.

Contudo, a experiência concreta dos indivíduos revela também outros processos que envolvem a percepção e, a partir dela, os modos pelos quais os indivíduos se relacionam com os meios (físico e sociocultural) em que estão inseridos (SIMONDON, 2005). Trata-se dos processos de "mudança" nos modos de perceber, isto é, da passagem de um modo constituído a outro modo (diferente) que se constitui. Para o indivíduo, que se satisfaz com a complacência do senso comum, esta experiência de passagem de uma percepção a outra é comodamente ignorada. Porém ela existe e habita abundantemente nossa vida cotidiana. $\mathrm{O}$ que então ela nos indica em sua efemeridade? Que há um processo contínuo de gênese das percepções, que ordinariamente tomamos como "dadas".

Pensar a gênese das percepções implica imediatamente compreender que toda forma de apreensão da realidade é construída, logo, que não há qualquer "dado natural" perceptivo, assim como qualquer "dado natural" do mundo. Ou melhor, que não há percepção nem mundo dados em si mesmos ontologicamente, mas que ambos resultam de um processo ontogenético ininterrupto de 
criação. Desse modo, não se trata mais de abordar apenas os "pontos de parada" na passagem de uma percepção a outra, mas buscar acompanhar o próprio movimento de gênese destas percepções, que posteriormente tendem a se "naturalizar" em função das necessidades práticas do vivo. Porém, devemos compreender esta "naturalização" ou "pontos de parada" perceptivos fora de uma perspectiva estática, compreendendo-os como modos de equilíbrio metaestáveis nos quais o aspecto inventivo permanece operando continuamente. Desse modo, esta perspectiva ontogenética implica, consequentemente, em problematizar uma concepção meramente estática e ontológica do mundo percebido, na medida em que não se pode pensar a gênese da percepção "descolada" da gênese do real. Portanto, o problema da gênese coloca a necessidade de uma outra maneira de abordar a percepção, isto é, exige uma política da percepção não apenas devotada à adaptação, mas direcionada também aos processos de criação e transformação dos fenômenos perceptivos. Assim, a imagem tradicional da teoria do conhecimento na qual a psicologia manteve-se apoiada e que separa e opõe sujeito e objeto (percepção e mundo dados ontologicamente), deve ser sobreposta por uma perspectiva em devir (ontogênese) que pensa a "percepção" e o "mundo" como "coemergentes", como duas dimensões da experiência que se distinguem, porém sem se separar.

Esta abordagem ontogenética da percepção demanda da psicologia um deslocamento para novas bases epistemológicas, abandonando o modelo clássico de ciência (que conduz à objetivação dos dados da experiência cognitiva), e adotando um modelo de ciência não mais comprometido com a definição exclusiva de um campo de saber que possuiria seu objeto específico. Logo, consideramos que a própria experiência cognitiva pode ser enriquecida com as contribuições de diversas áreas do saber, tais como a biologia, a etologia, a filosofia e as artes. Apreendido em sua gênese, o processo perceptivo extrapola os limites que as perspectivas clássicas tentam lhe impor à custa da objetividade e se expressa numa dinamicidade heterogênea que melhor permite ser acompanhada por uma perspectiva "transdisciplinar".

De acordo com Gondar (2002; 2005), é preciso não confundir esta perspectiva com uma simples colaboração entre diversas disciplinas, onde cada qual contribuiria, separadamente, com seu saber especializado em torno de um mesmo objeto (multidisciplinaridade), nem com uma tentativa conjunta de reconciliação entre disciplinas sobre um tema comum, porém sem que cada uma delas coloque em questão a estrutura do saber que lhes garantem identidade e unidade próprias (interdisciplinaridade). Em ambos os casos, as fronteiras que mantém a ordem das disciplinas são preservadas. De outro modo, a noção de transdisciplinaridade busca romper com os limites entre as disciplinas, constituindo-se como uma "atitude crítica" que põe em questão tanto a identidade do sujeito que conhece quanto do objeto conhecido. Esta desestabilização da dicotomia sujeito/objeto termina, enfim, por produzir uma subversão dos limites que sustentam a unidade das disciplinas e dos especialismos (PASSOS;
BARROS, 2000). Esta atitude visa, portanto, produzir efeitos de transversalidade ${ }^{1}$ entre os diversos saberes, tendo por resultado a produção tanto do objeto quanto do sujeito que coemergem nas práticas de conhecimento. Assim, ao invés de supor a preexistência dos termos que se distinguem e se opõem, a perspectiva transdisciplinar busca traçar o mapa de sua gênese, compreendendo o par sujeito/objeto como termos que se constituem a partir de uma relação singular.

No que diz respeito ao objeto de nossa investigação, o fenômeno da percepção se determina continuamente como "relação", delineando singularmente o "sujeito" percipiente e o recorte da "realidade" correspondente. Nesta perspectiva transdisciplinar, a não preexistência de um "dado" do mundo e de um "observador", anteriores à experiência perceptiva, nos permite pensar a gênese da percepção como um "perspectivismo"2 em processo. Em algumas abordagens oriundas de campos diversos do saber científico, os processos de gênese dos fenômenos perceptivos são pensados de acordo com esta perspectiva. Como exemplo, podemos mencionar inicialmente os trabalhos do zoólogo estoniano Jacob von Uexküll (1982), um dos pioneiros da Etologia. Sua principal contribuição foi a elaboração da "doutrina do mundo-próprio" (Umwelt), segundo a qual a percepção é indissociável da ação nos sujeitos vivos e que as formas de conexão entre o mundo da percepção (Merkwelt) e o mundo da ação (Wirkwelt) formariam ciclos de funções perfeitamente determinados. O número de ciclos de função comporia, portanto, o mundo próprio de uma determinada espécie animal, de modo que "todos os sujeitos animais, os mais simples como os mais complexos, estão ajustados com a mesma perfeição aos seus mundos-próprios" (UEXKÜLL, 1982, p. 36).

O problema ao qual Uexküll se dedicou consistiu em observar que, dentro de um mesmo "mundo ambiente" (Umgebund), diversas espécies animais conectam suas ações a distintos "sinais característicos" (estímulos), expressando cada qual seu "mundo-próprio" (Umwelt). Assim, todo o opulento mundo ambiente que rodeia cada espécie animal é contraído e transformado num "quadro mesquinho" de apenas poucos estímulos aos quais suas ações reagem, formando o seu mundo-próprio. A questão que Uexküll coloca é: entre centenas ou milhares de "estímulos" presentes no mundo ambiente, porque as espécies "percebem" somente alguns poucos aos quais direcionam suas ações? Com esta questão, Uexküll coloca em xeque o "estatuto ontológico da realidade", deslocando-a de uma existência "em si", dada para todos os seres viventes. Desse modo, o etólogo nos adverte contra a ilusão relativista que "é alimentada pela suposição da existência de um mundo único em que todos os seres vivos estão encerrados" [...] e "de que deve haver um único espaço e um único tempo para todos os seres vivos" (UEXKÜLL, 1982, p. 42). É preciso, ao contrário, compreender sua "doutrina do mundo-próprio" como um "perspectivismo" no qual cada espécie animal constrói o

${ }^{1}$ Sobre a noção de transversalidade, ver Guattari (2004).

${ }^{2}$ Sobre a relação entre o perspectivismo e a gênese da subjetividade, ver: Melo (2011). 
seu próprio "mundo de percepção" indissociável do seu próprio "mundo de ação". Então, ao invés de uma única realidade que seria relativa a cada espécie animal, haveria uma realidade perspectiva singular que comporia parte do mundo-próprio de cada uma das espécies. ${ }^{3}$

Outra abordagem que encontra ressonância com a "doutrina do mundo-próprio" de Uexküll é a "abordagem enativa da cognição" do biólogo Francisco Varela. Em ambas, o processo cognitivo tem por base o fenômeno da vida, expresso pela relação de um corpo vivo singular com o meio que o envolve. Tanto em Uexküll quanto em Varela, o corpo é compreendido a partir de suas capacidades sensório-motoras, embora para este último tais capacidades se realizem não somente num contexto biológico, mas também cultural. A perspectiva de Varela consiste numa reação crítica às abordagens estritamente abstratas das ciências cognitivas, onde a cognição é reduzida a um processo formal de processamento de informações descolado da experiência vivida num contexto concreto (biológico/cultural). Neste sentido, Varela (2003, p. 79) afirma que "o ponto de partida para a abordagem enativa é o estudo sobre como o 'sujeito percipiente' orienta suas ações em situações locais”, de modo que as faculdades cognitivas são ligadas ao histórico do que é vivido pelo sujeito. Derivado do inglês to enact, enação é um conceito cunhado por Varela (1996) que significa "efetuar", "pôr em ato", "atuar", marcando a indissociabilidade entre a ação e o ator, entre o fazer e o ser, de modo que o sujeito não tem uma preexistência independente de sua ação no mundo. Mas o mundo também não preexiste ao sujeito da ação, pois "coemerge" com ele no próprio ato, o que marca o "aspecto ontogenético" de sua perspectiva cognitiva. Disto depreende-se que o mundo muda a partir das ações do sujeito. O "novo mundo" percebido incita, por sua vez, "novas ações" do sujeito, que mais uma vez mudam o mundo, possibilitando novas ações, e assim sucessivamente, seguindo uma deriva de auto-engendramento do sujeito e do mundo no decorrer das situações concretas vividas.

O que se vê nesta perspectiva é a sucessiva conexão entre percepção e ação, num sentido muito próximo ao elaborado por Uexküll. O caráter histórico desta operação revela, por sua vez, o modo como se opera a gênese dos modos de perceber do sujeito e da realidade a ele atrelada por meio de suas ações. Segundo Varela (2003), é através da recorrência entre uma determinada "situação concreta percebida" e uma "prontidão para ação" a ela associada que emergem, ao mesmo tempo, os "micromundos" e as "microidentidades". Deste modo, o aspecto recorrente da conexão entre percepção e ação forma não somente o conjunto das estruturas cognitivas corporificadas, mas também dá à realidade, que emerge na percepção, um caráter concreto. Contudo, o concreto para Varela não é sinônimo de estabilidade, como se a realidade ganhasse

\footnotetext{
${ }^{3}$ Esta ilusão relativista está presente em algumas das abordagens da psicologia animal, sobretudo no Behaviorismo e no Gestaltismo (FERREIRA, 2010; PENNA, 1973). Em tais perspectivas da psicologia, há um preconceito do experimentador em atribuir ao campo experimental a "presença" dos estímulos a serem percebidos pelo animal. No entanto, de acordo com Uexküll (1982, p. 41), "este mundo ambiente não é mais do que o nosso mundo-próprio humano" que projetamos sobre o mundo-próprio do animal nas situações experimentais.
}

aí um estatuto ontológico definitivo. O concreto é o lugar da ontogênese que nos liga ao presente da experiência onde a subjetividade e a realidade emergem simultaneamente, porém esta emergência é sempre problematizada, o que põe nossa cognição em um contínuo devir. Assim, diferentemente das máquinas inteligentes que simulam a cognição humana em situações artificiais, nossos micromundos e microidentidades são frequentemente abalados por colapsos (problemas) para os quais não possuímos respostas no repertório de nossos esquemas cognitivos. Os colapsos nos forçam a engendrar novos recortes perceptivos e novas ações apropriadas a eles com vista à sua resolução. Dessa maneira, os colapsos nos colocam numa "deriva inventiva de percepções e ações" que fazem "novos mundos" surgirem e "novas capacidades sensório-motoras" emergirem. Enfim, segundo Varela (2003, p. 78), "são os colapsos que constituem a origem do lado autônomo e criativo da cognição viva", fazendo coemergir sujeito e mundo/objeto na experiência concreta.

Apesar de apostar no aspecto de criação da subjetividade e do mundo, esta perspectiva enativa revela que a cognição possui em si a "tendência de resolver os problemas" que são colocados nos contextos biológicos e culturais. Movida pelo impulso de perseverar na existência, a vida encontra nos processos adaptativos um meio para esta finalidade em todos os seres viventes. Em todo o reino animal, a ferramenta basicamente utilizada em prol desta garantia é o "instinto", enquanto que para alguns antropóides ${ }^{4}$ e para os seres humanos também se desenvolveu a "inteligência" (BERGSON, 2005). Em ambos os casos, o ponto de partida é a constituição dos corpos vivos a partir de duas faces, sensorial e motora, que diferem em complexidade entre as espécies animais. De um lado, a percepção estabiliza as imagens a partir de um recorte do meio, e de outro, o vivo elabora e efetua a ação mais apropriada de maneira a tirar proveito da situação em que está inserido. Assim, as formas de resolução de problemas diferem a cada espécie, porém mantém-se com o mesmo propósito: garantir a adaptação do ser vivo.

Neste sentido, de acordo com o filósofo Henri Bergson (2006, p. 158), a percepção é um auxiliar da ação, "ela isola, no conjunto da realidade, aquilo que nos interessa; mostra-nos menos as coisas mesmas do que o partido que delas podemos tirar". Da relação e do ajustamento entre percepções e ações, em cada espécie, resulta a formação de esquemas habituais ou automáticos que terminam por "naturalizar" ou corporificar o conjunto dos "dados úteis" do meio como constituindo a própria realidade. Há, portanto, uma coemergência de percepção e ação, tal como Varela nos apontou acima, no entanto sem ressaltar que este processo coemergente é conduzido por um princípio utilitário e adaptativo. Assim, a percepção utilitária fornece uma imagem estática e indubitável da realidade sobre a qual a ação, também utilitária, irá incidir.

Esta imagem ou conjunto de imagens que dão à realidade um aspecto "natural" constituem, no caso específico da percepção humana, o que o terapeuta corporal Hubert

${ }^{4}$ Experiências de resolução de problemas com chimpanzés na perspectiva da psicologia da Gestalt são relatadas em: Köhler (1978).

Fractal, Rev. Psicol., v. 29 - n. 2, p. 103-109, 2017 
Godard (2006) chama de "olhar objetivo", ou objetivante, ligado à história do indivíduo e também à linguagem, e que contribui para imputar um "aspecto ontológico" à realidade percebida. Neste sentido, o que ordinariamente denominamos como "atenção" não passa desta forma de apreender a realidade a partir de uma perspectiva estritamente objetiva, passando de um "dado" a outro, ou por aspectos mais ou menos complexos de um ou vários "dados" de uma mesma realidade objetivada.

Até aqui vimos algumas indicações de como se dá a gênese da "percepção natural" (BERGSON, 1990), ou melhor, das perspectivas objetivas que se produzem a partir da relação entre nosso corpo e o mundo material que nos envolve no decorrer de nossa história. No entanto, este processo de objetivação da realidade nos faz "virar as costas" ao processo contínuo de gênese da percepção que viabiliza sua transformação e assentarmo-nos sobre as perspectivas já constituídas em nossa experiência. Desse modo, passamos a ignorar a possibilidade de retomar os processos de gênese e de fazermos mudar ou variar nossas perspectivas sobre o "mundo conhecido". É justamente esta possibilidade que nos incita a delinear o problema que pretendemos abordar, partindo do seguinte questionamento: como compreender a percepção a partir de uma perspectiva ontogenética, isto é, como um processo contínuo e heterogêneo responsável tanto pela emergência dos "dados" objetivos, que possibilitam nossas ações utilitárias, quanto pela mudança de nossos modos de perspectivar a realidade, que permite transformar nossas configurações subjetivas?

Dito de outro modo, nossa proposta de investigação pode ser colocada da seguinte maneira: ao invés de pensar a gênese da percepção a partir dos dados objetivos já constituídos e estáveis em nossa subjetividade, buscar compreender como estes dados emergem de um processo relacional metaestável que se mantém continuamente sob a forma de tensão entre nosso corpo e o ambiente em que estamos inseridos. Segundo nossa hipótese, o acesso a este processo metaestável que permite a ampliação das nossas faculdades de perceber tem por condição a suspensão dos laços utilitários entre nossos modos automatizados de perceber e agir.

Alguns dos autores supracitados oferecem indicações que nos auxiliarão a pensar um desenvolvimento inicial desta questão, entretanto é o filósofo Merleau-Ponty (2004, p. 1) quem melhor apresenta o delineamento disparador de nossa problemática, ele nos diz:

O mundo da percepção, isto é, o mundo que nos é revelado por nossos sentidos e pela experiência de vida, parece-nos à primeira vista o que melhor conhecemos, já que não são necessários instrumentos nem cálculos para ter acesso a ele e, aparentemente, basta-nos abrir os olhos e nos deixarmos viver para nele penetrar. Contudo, isso não passa de uma falsa aparência. [...] Esse mundo é em grande medida ignorado por nós enquanto permanecemos numa postura prática ou utilitária.
A filosofia de Bergson (2006, p. 157), por sua vez, expressa uma direção semelhante à de Merleau-Ponty, ao considerar que a visão que ordinariamente temos dos objetos exteriores e de nós mesmos é:

[...] uma visão que nosso apego à realidade, nossa necessidade de viver e de agir, nos levou a estreitar e esvaziar; [...] e que as necessidades da ação tendem a limitar o campo da visão; [...] [de modo que] a percepção distinta é simplesmente recortada, pelas necessidades da vida prática, num conjunto mais vasto.

No entanto, Bergson e Merleau-Ponty vão além ao propor duas vias possíveis que nos possibilitariam expandir nossas faculdades de perceber: a arte e a própria filosofia. Nas palavras de Merleau-Ponty (2004, p. 1-2), "um dos méritos da arte e do pensamento modernos [...] é o de fazer-nos redescobrir esse mundo em que vivemos, mas que somos sempre tentados a esquecer". Para Bergson (2006, p. 159), haveria uma operação comum à arte e à filosofia no sentido de ampliar as faculdades de perceber que consiste em produzir um deslocamento da nossa atenção utilitária: "tratar-se-ia de afastar essa atenção do lado praticamente interessante do universo e de voltá-la para aquilo que, praticamente, de nada serve". Por fim, Godard (2006, p. 73) nos diz que o "olhar objetivo" coexiste com um "olhar subjetivo", que "é um olhar através do qual a pessoa se funde no contexto, não há mais um sujeito e um objeto, mas uma participação no contexto geral. Então, esse olhar não é interpretado, não é carregado de sentido".

Inspirado na perspectiva da artista e terapeuta brasileira Lygia Clark, Godard ressalta a importância do olhar subjetivo tanto no campo da criação da obra de arte quanto no campo da clínica psicoterápica. Neste sentido ele aponta que Lygia Clark realizou uma "revolução no nível da percepção" tanto em suas obras de arte quanto em sua abordagem clínica, já que "as duas trabalham sobre uma remodelagem e uma recolocação da percepção em movimento" (GODARD, 2006, p. 75). No entanto, é preciso compreender que esta "revolução da percepção" não consiste em substituir o "olhar objetivo" pelo "olhar subjetivo", mesmo que Lygia Clark aponte sempre a importância deste último para a criação da arte e da subjetividade, mas em produzir um movimento de ir e vir entre ambos. Assim, parte-se da ideia de que os dois operam ao mesmo tempo, mas que a recorrência histórica de nossa percepção produzirá um filtro através do qual passamos a perceber "sempre a mesma coisa" e encontramos dificuldade em "reinventar os objetos do mundo", constituindo o que Lygia Clark denominou de "neurose do olhar".

A direção do tratamento, nesta perspectiva, consistiria então em buscar de alguma maneira mover esse filtro, mas como? Godard nos indica:

Pode-se ver que nos dispositivos, nos acontecimentos ou coisas desta ordem, realizados por Lygia, há uma tentativa de modificar essa posição do olhar, de refazer um mergulho num olhar subjetivo onde há uma perda das noções gravitacionais e outras, permitindo atingir um olhar talvez mais primeiro ou menos manchado de linguagem, [...] o que per- 
mite participar completamente das coisas do mundo antes de engessá-las numa interpretação (2006, p. 73, grifo do autor).

Enfim, é sempre rumo ao "olhar subjetivo" que a trajetória de Lygia Clark se pôs em movimento, possibilitando que abandonemos essa espécie de segurança do "olhar objetivante" a partir dos encontros que ela cria com o inaudito através dos materiais de sensibilização dos sentidos, fazendo do corpo o lugar onde a intervenção clínica e a criação artística se tornam indiscerníveis. Neste sentido, embora Lygia Clark se expresse em termos de "olhar", a percepção deve ser compreendida como um fenômeno por meio do qual todo o corpo se relaciona com aspectos intrapsíquicos e extracorpóreos, ou seja, como um processo de "mediação" entre a interioridade subjetiva e a exterioridade objetiva do mundo que envolve o corpo. Este processo de relação mediadora dos sentidos de si e do mundo, pela percepção, nos oferece uma compreensão da "corporeidade" como um processo contínuo e paradoxal de produção de automatismo e de criação, de contração e de expansão, de corporificação e de mudança.

Por fim, essa experiência paradoxal expressa entre as duas modalidades da percepção propostas por Lygia Clark, ilustra a nossa hipótese de uma "perspectiva ontogenética" dos fenômenos perceptivos. Isto é, ao invés de simplesmente partir dos aspectos "objetivados" da percepção, buscar compreender e fazer emergir seus aspectos "subjetivos" que são condição de toda objetivação e de toda transformação da percepção objetiva. É justamente a compreensão e a emergência deste aspecto "subjetivo" que põe a percepção em movimento que pretendemos trazer para o debate com as teorias e sistemas psicológicos, a fim contribuir para a ampliação do campo conceitual da psicologia, tanto no que diz respeito aos aspectos teóricos dos estudos dos processos cognitivos quanto no plano prático das intervenções terapêuticas. Concluímos, portanto, que o estudo da gênese e da transformação da percepção implica, não apenas para estes campos supracitados, mas para a diversidade de todo o campo da psicologia, em tornar extremamente relevante o papel do corpo enquanto sede de emergência dos processos psicológicos e foco de intervenção clínica, fazendo da vida que nele encarna um contínuo movimento paradoxal de corporificação estruturante e diferenciação.

\section{Referências}

BERGSON, H. Matéria e memória: ensaio sobre a relação do corpo com o espírito. São Paulo: Martins Fontes, 1990.

BERGSON, H. As direções divergentes da evolução: torpor, instinto e inteligência. In: A evolução criadora. São Paulo: Martins Fontes, 2005. p. 105-201.

BERGSON, H. A percepção da mudança. In: . $O$ pensamento e o movente. São Paulo: Martins Fontes, 2006. p. 149-182.

CANGUILHEM, G. Le normal et le pathologique. Paris: PUF, 2003.

DELEUZE, G. A imagem do pensamento. In: Diferença e repetição. Rio de Janeiro: Graal, 1988. p. 216-273.
DELEUZE, G. Francis Bacon: lógica da sensação. Rio de Janeiro: J. Zahar, 2007.

DEWEY, J. O conceito de arco reflexo. In: BORING, E. G.; HERRNSTEIN, R. J. (Org.). Textos básicos de história da Psicologia. São Paulo: Herder/Edusp, 1971. p. 197-220.

DO EIRADO, A. et al. Memória e alteridade: o problema das falsas lembranças. Mnemosine, Rio de Janeiro, v. 2, n. 2, p. 75$86,2006$.

DO EIRADO, A. et al. Estratégias de pesquisa no estudo da cognição: o caso das falsas lembranças. Psicologia \& Sociedade, Florianópolis, v. 22, n. 1, p. 84-94, jan./abr. 2010. Cross ${ }^{\text {Ref. }}$

FERREIRA, A. A. L. (Org.). Percepção. In: . $A$ pluralidade do campo psicológico. Rio de Janeiro: UFRJ, 2010. p. 215-251.

FOUCAULT, M. A psicologia de 1850 a 1950. In: MOTTA, M. B. (Org.). Problematização do sujeito: Psicologia, Psiquiatria e Psicanálise. Rio de Janeiro: Forense Universitária, 1999. Coleção Ditos \& Escritos, v. 1, p. 133-151.

GODARD, H. Olhar cego. Entrevista com Hubert Godard, por Suely Rolnik. In: Lygia Clark: da obra ao acontecimento. Somos o molde. A você cabe o sopro. São Paulo: Pinacoteca do Estado de São Paulo, 2006. p. 73-80.

GONDAR, J. Ciências humanas e transdisciplinaridade: a relação da ciência com a linguagem. História \& Perspectivas, Uberlândia, n. 25/26, p. 81-97, 2002.

GONDAR, J. Quatro proposições sobre memória social. In: GONDAR, J.; DODEBEI, V. (Org.). O que é memória social? Rio de Janeiro: Contra-Capa, 2005. p. 11-26.

GUATTARI, F. A transversalidade. In: Psicanálise e transversalidade: ensaios de análise institucional. Aparecida, SP: Ideias e Letras, 2004. p. 101-117.

GUILLAUME, P. Psicologia da forma. São Paulo: Companhia Editora Nacional, 1960

KASTRUP, V. A invenção de si e do mundo. Campinas: Papirus, 1999.

KAStruP, V.; Tedesco, S.; PASSOS, E. Políticas da Cognição. Porto Alegre: Sulina, 2008.

KOFFKA, K. Princípios de psicologia da Gestalt. São Paulo: Cultrix/Edusp, 1975.

KÖHLER, W. A inteligência dos antropoides. In: ENGELMANN, A. (Org.). Wolfgang Köhler: psicologia. São Paulo: Ática, 1978. p. 39-56.

MELO, D. Subjetividade e perspectivismo: a dissolução do sujeito metafísico a partir de uma lógica das relações em Nietzsche. Revista Trágica: estudos sobre Nietzsche, Rio de Janeiro, v. 4, n. 1, p. 25-36, $1^{\circ}$ sem. 2011. Disponível em: $<$ http://tragica.org/artigos/v4n1/02-danilo.pdf>. Acesso em: 12 ago. 2016 .

MERLEAU-PONTY, M. Conversas - 1948. São Paulo: Martins Fontes, 2004.

PASSOS, E.; BARROS, R. A construção do plano da clínica e o conceito de transdisciplinaridade. Psicologia: Teoria e Pesquisa, Brasília, v. 16, n. 1, p. 71-79, jan./abr. 2000. Cross ${ }^{\text {Ref. }}$

PENNA, A. G. Percepção e Realidade. Rio de Janeiro: Fundo de Cultura, 1973. 
PENNA, A. G. Introdução à psicologia cognitiva. São Paulo: EPU, 1999.

PIAGET, J. Les mechanisms perceptifs. Paris: PUF, 1961.

SEIDL DE MOURA, M. L.; CORREA, J. Introdução ao estudo psicológico do pensamento: de W. Wundt ao projeto de uma ciência da cognição. Rio de Janeiro: EDUERJ, 1997.

SIMONDON, G. L'Individuation à la lumière des notions de forme et d'information. Grenoble: Jérôme Millon, 2005.

SIMONDON, G. Cours sur la Perception (1964-1965). Chatou: Les Éditions de la Transparence, 2006.

SIMONDON, G. Du mode d'existence des objets techniques. Paris: Aubier, 2012.

SKINNER, B. F. Sobre o Behaviorismo. São Paulo: Cultrix/ Edusp, 1974.

UEXKÜLL, J. von. Dos animais e dos homens. Lisboa: Livros do Brasil, 1982.

VARELA, F. Invitation aux sciences cognitives. Paris: Seuil, 1996.

VARELA, F. O reencantamento do concreto. São Paulo: Cadernos de Subjetividade, 2003.

WERTHEIMER, M. Leis da Gestalt e fatores de organização. In: SAHAKIAN, W. S. (Org.). Aprendizagem: sistemas, modelos e teorias. Rio de Janeiro: Interamericana, 1980. p. 32-49.

Recebido em: 13 de novembro de 2016

Aceito em: 2 de junho de 2017 